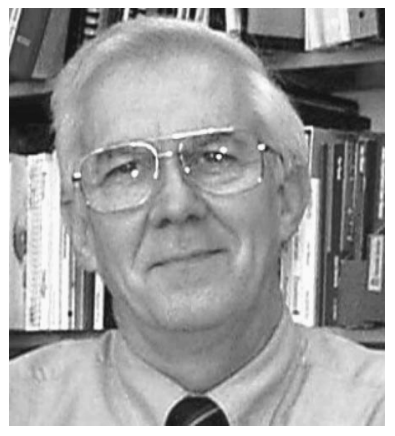

\section{0 in Review}

As in previous years, I want to report on the state of this journal at the end of 2000. In contrast to last year's smaller issues, this year Optical Engineering returned to the size and heft of previous years. The difference is so dramatic, that I have included the statistics from 1998 and 1999 to give a true appreciation of the drop and rebound in the size of the publication (see Table 1). Note that the numbers for 1998 and 2000 are nearly the same.

What happened during 1999 and why? One answer may be in the mix of regular submissions compared to special section papers. Special sections are edited by guest editors, who are experts in the topic of the section. They are responsible for the call for papers, the review of papers, and the decisions on publication of submitted papers. In comparison, regular papers are submitted without a call and are handled by members of the Board of Editors. In the past, special sections contributed fully one third of the papers to the journal. In 1999 it was a quarter of the papers. This past year only one fifth of the papers in the journal were part of special sections (Table 2).

Over the three-year period the number of regular papers received has increased modestly, while the number of special section papers has fallen drastically. This has been due to a reduction in the number of special sections. It was a conscious choice based on maintaining a high editorial standard. A special section just for the sake of additional pages is not a good idea.

But that's not to say that special sections should be suspect. Rather, these sections should highlight new fields and innovative segments of old fields. I am proud to say that the special section on Pushing the Envelope in Opti-

Table 1 Major statistics for 1998-2000 and percentage changes from 1999.

\begin{tabular}{lrrrc}
\hline & 1998 & 1999 & 2000 & 2000 vs 1999 \\
\hline Number of journal pages & 3336 & 2212 & 3360 & $+51.9 \%$ \\
Number of technical pages & 3164 & 2045 & 3220 & $+57.5 \%$ \\
Number of papers published & 413 & 273 & 412 & $+50.9 \%$ \\
\hline
\end{tabular}

Table 2 Regular vs special section papers for 1998-2000 and percentage changes from 1999.

\begin{tabular}{lccccc}
\hline & 1998 & 1999 & 2000 & 2000 ratio & 2000 vs 1999 \\
\hline $\begin{array}{c}\text { Regular papers } \\
\text { published }\end{array}$ & 275 & 209 & 332 & $80.6 \%$ & $+58.9 \%$ \\
$\begin{array}{c}\text { Special papers } \\
\text { published }\end{array}$ & 138 & 64 & 80 & $19.4 \%$ & $+25.0 \%$ \\
$\begin{array}{c}\text { Regular papers } \\
\text { received }\end{array}$ & 485 & 518 & 525 & & $+1.4 \%$ \\
$\begin{array}{c}\text { Special papers } \\
\text { received }\end{array}$ & 94 & 78 & 29 & & $-62.8 \%$ \\
\hline
\end{tabular}

cal Design Software grew out of a conversation with Mary Turner of Focus Software during an SPIE reception. SPIE members have told me that they miss papers in the more applied fields of optical engineering. I continue to look for opportunities to present material in those disciplines that tend to be overlooked because the researchers do not tend to publish beyond a quick proceedings paper.

One effort to include more proceedings authors is a procedure called "paper mining." It is a method for identifying outstanding papers at SPIE conferences through the conference chairs. The authors are issued invitations to prepare an archival version of their work for Optical Engineering.

Another possible source of increase in the number of published papers is the increased acceptance rate, something I would regard as a loss of standards. But as can be seen from Table 3, the acceptance rate has increased modestly (11 papers out of 474!). Overall, I am encouraged by the return to the publication numbers of previous years.

The distribution in the authors is as varied as ever (see Tables 4 and 5). While the largest number of papers (145) comes from the United States, the majority of papers come from the rest of the world, emphasizing the "International' in SPIE's descriptor. The two regions that contribute the most are Asia (119) and Europe (79). Within the United States, California continues to be the largest source of papers, but Texas, Florida, and Massachusetts, states that had been in eighth, fifteenth, and eighteenth place last year, returned to the top of the heap. (Maybe that's why we had such a drop in papers last year!) 
Table 3 Outcomes of papers acted on in 1999 and 2000 (regular papers only).

\begin{tabular}{lrrrr}
\hline & \multicolumn{2}{l}{1999} & \multicolumn{2}{l}{2000} \\
\hline Accepted & 284 & $59.54 \%$ & 295 & $62.25 \%$ \\
Declined & 116 & $24.32 \%$ & 106 & $22.36 \%$ \\
Closed & 70 & $14.68 \%$ & 67 & $14.14 \%$ \\
Withdrawn & 5 & $1.05 \%$ & 4 & $0.84 \%$ \\
Transferred & 2 & $0.42 \%$ & 2 & $0.42 \%$ \\
Total & 477 & $100 \%$ & 474 & $100 \%$ \\
\hline
\end{tabular}

Table 4 Number of papers published by region of first author in 1999 and 2000

\begin{tabular}{lrr}
\hline Region & 1999 & 2000 \\
\hline Africa & - & 3 \\
Asia & 77 & 119 \\
Australia & 8 & 7 \\
Eastern Europe & 13 & 19 \\
Middle East & 10 & 18 \\
North America & 108 & 163 \\
South/Central America & 6 & 4 \\
Western Europe & 51 & 79 \\
\hline
\end{tabular}

Table 5 Number of papers published from the U.S. in 2000 by state of first author.

\begin{tabular}{lc}
\hline State & Number \\
\hline California & 23 \\
Texas & 12 \\
Florida; Massachusetts & 11 \\
Arizona & 9 \\
Maryland & 8 \\
Alabama; Michigan; Pennsylvania & 6 \\
New York; Ohio; Virginia & 5 \\
Connecticut; Illinois; New Mexico & 4 \\
Indiana; Tennesee; Washington, DC & 3 \\
New Hampshire; New Jersey; North Carolina; & 2 \\
Wisconsin & \\
Arkansas; Colorado; Delaware; North Dakota; South & 1 \\
Carolina; Utah; Vermont; Washington; West Virginia & \\
\hline
\end{tabular}

Table 6 Activity of the editorial office in 2000 (regular papers only).

\begin{tabular}{lrc}
\hline & Number & \% change vs 1999 \\
\hline Reviewers selected & 1861 & +36.04 \\
Reviews received & 846 & -10.38 \\
Revised manuscripts received & 315 & +0.64 \\
Papers returned to authors & 388 & -6.95 \\
for revision & & \\
Communication papers received & 18 & +5.88 \\
OE Letters received & 22 & - \\
\hline
\end{tabular}

All this activity is supported by the submission and review process. One of the striking changes in the past year has been the increase of electronic submissions. About $20 \%$ of those submitting papers in 1999 sent them to Optical Engineering using the Internet, although the service was not begun until Spring of 1999. This year half of the papers received were sent to the SPIE journals department electronically. A remarkable acceptance of this new option for paper submission! If you would like to see a description of the procedure, it can be found on SPIE Web at http://www.spie.org/web/journals/ electronsub.html.

The review process has also benefited from these electronic procedures. Previously, papers were mailed to prospective reviewers along with a request to review. This was an inefficient process, because some did not respond and this lengthened the time to get acceptable reviews. Now requests to review are done by e-mail with a PDF file containing the abstract attached. The result is that we end up querying more prospective reviewers (see Table 6 ), but response time has been reduced. If the reviewer wishes, we can now send the manuscript as a PDF file, also. I thank all of our reviewers who contributed to maintaining the high standards we have come to expect.

One other item in Table 6 is the last line, "OE Letters received.' Introduced in August, this new feature for this journal has obviously begun to have an effect on the journal submissions. Right now, it is too early to tell how important OE Letters will become, but there will be an update a year from now.

I want to thank the members of the Board of Editors for their contributions toward maintaining these standards. I want to thank Henri Arsenault, Hugo Thienpont, and Frank Wyrowski, who have been on the Board since it was established three years ago. Richard Hoover has been excused because he will be SPIE President this year. Thanks are also due Gary Kamerman, Chris Koliopoulos, and Gerard Mourou for their service to Optical Engineering.

I must thank the journal staff. If you look on the masthead of this journal, you will see that four people are responsible for getting papers reviewed, copy edited, proofed, and printed. They have been instrumental in improving the electronic review process and in the start-up of OE Letters. Finally, I thank Roger Lessard for taking over for me during my year as SPIE president. This journal is the product of a wonderful community of researchers, reviewers, editors, and staff, who take their obligations seriously and produce something of worth.
Donald C. O'Shea Editor 